\title{
Profile of Afatinib and its Potential in the Treatment of Head and Neck Cancer: Current Evidence
}

Denaro $\mathbf{N}^{*}$ and Merlano MC

Department of Clinical Oncology S. Croce University Hospital, Cuneo, Italy

"Corresponding author: Denaro N, Department of Clinical Oncology, S. Croce University Hospital, Cuneo, Italy, Tel: 39-3202216583; E-mail: nerinadenaro@hotmail.com

Rec date: September 16, 2015; Acc date: October 27, 2015; Pub date: November 4, 2015

Copyright: ( 2015 Denaro $\mathrm{N}$ et al. This is an open-access article distributed under the terms of the Creative Commons Attribution License, which permits unrestricted use, distribution, and reproduction in any medium, provided the original author and source are credited.

\begin{abstract}
Head and neck squamous cell carcinoma (HNSCC) is the sixth most common cause of cancer death worldwide. About two thirds of patients present with locally advanced disease (LAHNC) (stage III e IV) in this setting a multidisciplinary approach is complex and evolving. In Recurrent/metastatic (R/M) HNSCC, Cetuximab, a monoclonal antibody against EGFR plus platinum - based chemotherapy (CT) allow overall survival (OS) of about 10 months. However prognosis for R/M-HNSCC remains dismal and additional efforts are needed. Currently no standard second line treatment may be offered to R/M HNSCC. Recent molecular breakthroughs in HNSCC and the use of new targeted therapies provide much hope for future strategies. Promising activity has been shown by target therapies beyond Cetuximab. Afatinib an irreversible inhibitor of the tyrosine kinase activity of EGFR family represents a promising drug to after first line failure and to overcome Cetuximab resistance.
\end{abstract}

Keywords: Afatinib; Head and neck cancer; HNSCC; EGFR

\section{Introduction}

Approximately two thirds of the patients with HNSCC presents with locally advanced disease. Fifty to $60 \%$ of patients with LA-HNSCC develop a loco-regional recurrence within 2 years. In addition, $20 \%$ to $30 \%$ of those patients develop distant metastases [1]. The scientific community recognized concurrent chemoradiation (CRT) as standard of care for locally advanced unresectable HNC after the publication of the pivotal Meta-analysis of chemotherapy in HNC (MACH-NC) [2].

In Recurrent/metastatic (R/M) HNSCC palliation is the goal and median survival did not overcome one year. Standard first line treatment include Cisplatin based chemotherapy plus Cetuximab. Cetuximab, a monoclonal antibody against EGFR, is indicated in LAHNSCC plus radiotherapy (RT) (for those ineligible for CRT) and in $\mathrm{R} / \mathrm{M}$ HNSCC with platinum based CT or in monotherapy after platinum failure. However, median overall survival still remains unsatisfactory, Cetuximab monotherapy overall response rate is modest (about 13\%) and no second line therapy has been approved. Extensive cross-talk between all ErbB-dependent signalling pathways in HNSCC, as well as the numerous molecular and genetic aberrations present, contribute to the development of Cetuximab resistance. Therefore there is an urgent need for new target therapies that overcome Cetuximab resistance and increase the therapeutic instruments. In addition to EGFR, other ErbB family members are expressed and activated in HNSCC [3,4]. Afatinib is an ErbB family blocker that has been approved for treating patients with EGFRmutated NSCLC. Afatinib activity has been compared in HNSCC cell lines with other EGFR-targeted agents, showing higher activity compared with Gefitinib and Cetuximab [5]. Afatinib, is being investigated in HNSCC treatment with encouraging phase II results, several phase III trials are ongoing and one phase III trial (LUX1) has been recently published. LUX-H\&N 1 evaluated Afatinib versus Methotrexate in R/M HNSCC patients following progression on platinum-based CT resulting in PFS $\mathrm{t}$ but not OS improvement. However results of the ongoing trials will help to understand the place of Afatinib in the HNSCC treatment armamentarium [6,7]. LUX-Head and Neck 2 a phase III study will assess adjuvant Afatinib versus placebo following CRT in primary unresected loco-regionally advanced intermediate-to-high-risk HNSCC [8].

\section{Material and Methods}

A comprehensive literature review was finalized in June 2015. Electronic search results were supplemented with hand searching of selected reviews, expert consensus meeting notes, and reference lists from selected articles. The literature search was limited to articles in English. The following Medical Subject Headings (MeSH) terms and keywords were used in the search: head and neck cancer, afatinib, personalized therapy, EGFR. Combination of Afatinib and "head and neck cancer" provided 32 papers of them 15 were not considered because off topic. Inclusion criteria were the following:

-papers in English language considering EGFR inhibition for recurrent or metastatic HNSCC

\section{-clinical studies}

We analysed and discussed the literature, taken into account the previous reported reviews on this matter.

\section{Profile of Afatinib}

EGFR is expressed in about $95 \%$ of HNSCC. Consolidated data evidenced that HNSCC with high EGFR protein expression display inferior 5-year overall survival rates, compared with patients with

HNSCC and low EGFR protein expression $(\mathrm{P}=0.029)[3,9]$.

Acquired resistance to Cetuximab has been linked to dysregulation of EGFR internalization or degradation, EGFR-dependent activation of human epidermal growth factor receptor 2 (HER2; ErbB2) and ErbB3, 
and increased signalling of alternative receptor tyrosine kinases, such as cMET. Irreversible blockade of all members of the ErbB family is an attractive target to overpass Cetuximab resistance. Irreversible inhibitors block all ErbB-mediated signalling pathways causing a sustained blockade of ErbB receptor dimers. This might lead to suppression of tumour growth and, improving efficacy.

Afatinib (Giotrif $)$, also known as BIBW 2992 (N-[4-[(3-chloro-4fluorophenyl) amino]-7-[[(3S)- tetrahydro-3-furanyl]oxy]-6quinazolinyl]-4-(dimethylamino)-2-butenamide; Figure $1 \mathrm{~A}$ and $1 \mathrm{~B})$, is an ATP competitive anilinoquinazoline derivative harbouring a reactive acrylamide group, capable of covalent binding to ErbB family and irreversible inhibition of EGFR, HER2 and HER4 [10,11]. Afatinib induces covalent modification of the EGFR, HER2 and Herb4 kinases domain activity that cause irreversible inhibition of enzymatic activity. Inhibition of autophosphorylation by Afatinib has been shown for Her2, EGFR and ErbB3 in several cellular lines and in some mouse models. Pathways inhibition was observed at low nanomolar concentration [11].

Afatinib retains inhibitory effects on signal transduction, cancer cell growth (both in vitro and in vivo) in tumours resistant to reversible EGFR inhibitors, such as those exhibiting the T790M, L858R mutations $[12,13]$.

The cytotoxic effect of Afatinib is greater than other TKIs [13]. This may depend on the effect on EGFR, Her 2 and Her4 while Erlotinib and Gefitinib only block EGFR. A number of explanations have been produced to explain why Afatinib is active in presence of multiple genetic aberration but in short consolidated data point to irreversible binding mode and anticipated tighter blockade [5]. Afatinib has recently been approved in several countries for the treatment of a distinct type of EGFR mutated non-small cell lung cancer (NSCLC) (USA in July 2013). Approval was based on findings from the pivotal phase III LUX-Lung 3 study, which demonstrated a median progression free survival of 11.1 months in patients treated with Afatinib versus 6.9 months in patients treated with chemotherapy $(\mathrm{P}<0.001)$ in the first-line EGFR mutation-positive setting [14-16]. In more recent analyses, an overall survival benefit with Afatinib versus chemotherapy was also observed in patients with NSCLC harbouring the EGFR Del19 mutation $[15,16]$.

\section{Afatinib potential in the treatment}

In HNSCC treatment options for R/M disease after platinum failure are limited. Therefore there is a need for an alternative second line. Current research is focused on molecular targeting therapies inhibiting EGFR; new treatments (binding covalently and irreversibly their targets) represent a promising field.

A comparison among Cetuximab and Afatinib after 2 lines of Cisplatin has been performed. The NCT00514943 randomised to Afatinib $50 \mathrm{mg}$ oral once daily, or Cetuximab $400 \mathrm{mg} / \mathrm{m}^{2}$ (loading dose) and $250 \mathrm{mg} / \mathrm{m}^{2}$ thereafter IV once weekly. Upon progression patients crossover to the opposite treatment (stage 2). Mean tumour shrinkage by independent radiological review (IRR) was not significative $(\mathrm{p}=0.761)$ while investigators assessed objective response rate (ORR) for intention to treat (ITT) analysis, $16.1 \%$ vs. $6.5 \% \mathrm{p}=0.09$, for evaluable patients, $19.2 \%$ vs. $7.3 \%$; median PFS by IRR, 15.9 wks (95\% CI 10.3-17.1) vs. 15.1 wks (95\% CI 8.3-19.1), by ICR, $13.0 \mathrm{wks}$ (95\% CI 8.0-20.0) vs. 15.0 wks (95\% CI 8.3-17.1). Among patients who crossed over Disease control rate (DCR) by IRR was $38.9 \%$ vs. $18.8 \%$. Most common treatment-related AEs, diarrhoea $78.7 \%$ vs. $20.2 \%$, rash/ acne $78.7 \%$ vs. $76.6 \%$; AEs leading to dose reduction, $29.5 \%$ vs. $3.3 \%$; AEs leading to discontinuation, $37.7 \%$ vs. $16.7 \%$ for Afatinib versus Cetuximab respectively $[17,18]$.

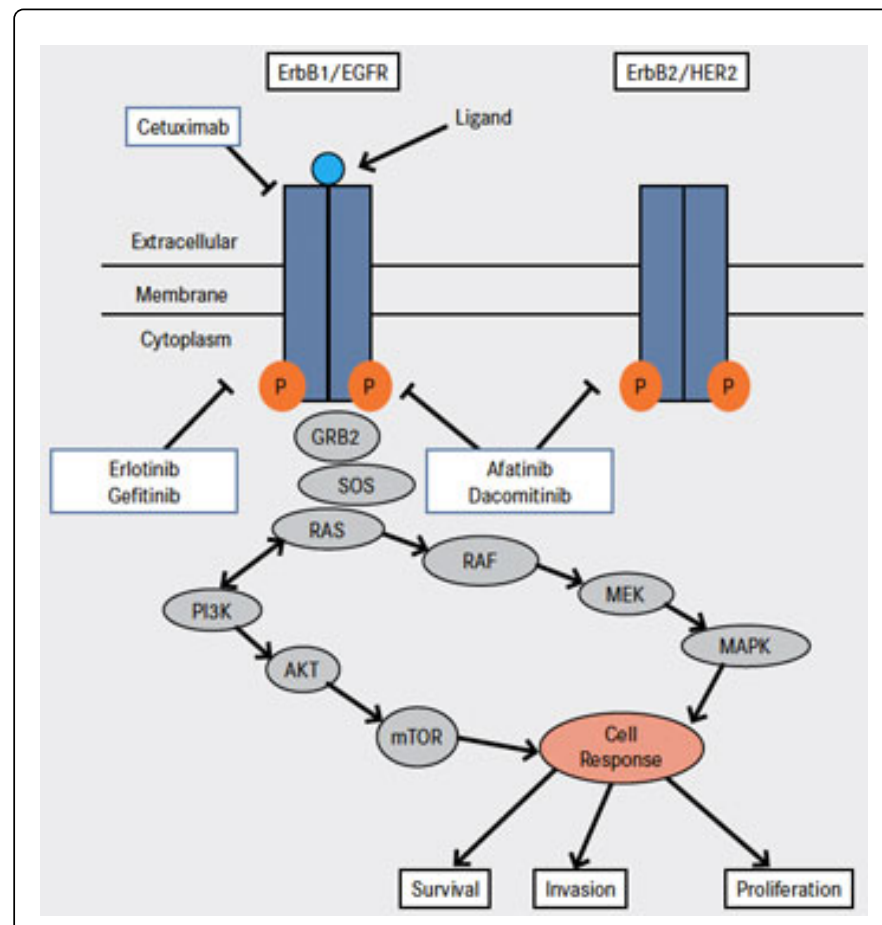

Figure 1A: Mechanism of action on EGFR family's proliferation pathway. Afatinib works to inhibit the function of two types of tyrosine kinases: epidermal growth factor receptor (EGFR) and Her2, which are "over-expressed".<smiles>CN(C)C/C=C/C(=O)Nc1cc2c(Nc3ccc(F)c(Cl)c3)ncnc2cc1OC1CCOC1</smiles>

Figure 1B: Chemical structure.

The LUX-H\&N1 study was conducted in 483 patients R/M HNSCC progressed after platinum based therapy (cisplatin or carboplatin), and many patients $(60 \%)$ had also received Cetuximab.

The primary end point of the study was progression-free survival (PFS) the secondary endpoints were overall survival, safety of Afatinib, quality of life assessment (deterioration of global health status, pain, swallowing impairment) and overall response rates. Median age was 60 years, $85 \%$ of the patients were male, and $80 \%$ were smokers. In the study, patients were randomized 2:1 to receive Afatinib $40 \mathrm{mg} /$ day orally or Methotrexate $40 \mathrm{mg} / \mathrm{m}^{2}$ per week. 
Page 3 of 5

A significant improvement in PFS (2.6 months with Afatinib vs. 1.7 months with Methotrexate; hazard ratio, $0.80 ; \mathrm{P}=.03$ ), was obtained. Although, the "small benefit" on PFS, not quite 1 month, do not strongly support its clinical utility. No improvement in overall survival (6.8 months with Afatinib vs. 6 months with Methotrexate), a secondary end point in this trial, was achieved [7]. Interestingly, a more pronounced benefit for PFS was noted in patients with baseline characteristics potentially linked to HPV negativity. Men, patients with cancer of the larynx, patients with locally recurrent versus metastatic disease, and heavy smokers ( $\geq 10$ pack-years) also seemed to derive more benefit with Afatinib than with Methotrexate in preplanned subgroup analyses. Moreover patients without previous treatment with EGFR-targeted therapy, with p16-negative disease, with locally recurrent disease, and with nonoropharyngeal cancer had a greater response with Afatinib. The authors reported that lack of OS improvement may depend on several reasons such as patient's population characteristics (10\%p16 pos $57 \%$ p16 not evaluable and $59 \%$ previous treated with EGFR Abs) and the use of subsequent anticancer therapies after progression (14-38\%), The most frequent grade 3 or 4 drug-related adverse events were rash or acne $(31$ (10\%) of 320 patients in the Afatinib group vs. none of 160 patients in the Methotrexate group), diarrhoea (30 (9\%) vs. three (2\%)), steatites $(20(6 \%)$ vs. 13 $(8 \%))$, fatigue $[18,19](6 \%)$ vs. five $[3 \%])$, and neutropenia $(1(<1 \%)$ vs. $11(7 \%))$; serious adverse events occurred in $44(14 \%)$ of Afatinibtreated patients and $18(11 \%)$ of Methotrexate-treated patients. In contrast, Afatinib significantly delayed the deterioration of global health status and the worsening of pain and swallowing when compared with Methotrexate (all secondary end points; P $\leq$ 0.3) [7].
A phase III trial, the LUX-H\&N 2 is ongoing, it is looking at Afatinib as adjuvant therapy in patients with LA-HNSCC.

In the subgroup analysis elderly patients treated with Afatinib had a better response as well as Cetuximab naive compared with those that had.

There was a better response seen among HPV neg patients compared with those who were positive (using p16 surrogate marker).

These clinical results showed that Afatinib safety is good. Comparison with Cetuximab showed that most common grade $\geq 3$ drug-related adverse events were rash/acne (18\% versus $8.3 \%)$, diarrhea $(14.8 \%$ versus $0 \%)$, and stomatitis/mucositis ( $11.5 \%$ versus $0 \%)$. Despite the greater proportion of drug related AEs observed with Afatinib, no differences in terms of QOL and outcomes were noted compared with Cetuximab [17].

In our experience compliance to treatment was great, patients took Afatinib either $1+$ hour before or $2+$ hours after a meal, without swallowing impairment. We did not reported sun sensitivity (we suggest a sun screen cream), we report dhiarroea G2 in about $30 \%$ of patients and G1 in the others. Skin rash appeared in $30 \%$ of patients, it was G2 but was ictchy for 1 patients.

Currently, 4 phase II-4 phase III studies in postoperative situation, 2 phase II in neoadjuvant setting and treatment using an anti-EGFR are in progress: 2 in concurrent chemoradiation and 1 both in concomitance and in adjuvant therapy with radiotherapy. Table 1 summarizes trials evaluating Afatinib in HNSCC clinical setting.

\begin{tabular}{|c|c|c|c|c|c|}
\hline Study & Type & Schedule & Description/objective & Status & Phase \\
\hline NCT01538381 & $\begin{array}{l}\text { Neoadjuvant Afatinib Window Study in } \\
\text { Squamous Cell Carcinoma of the Head and } \\
\text { Neck }\end{array}$ & $\begin{array}{l}\text { Afatinib } 40 \mathrm{mg} / \text { day p.o. per } 2 \\
\mathrm{w}\end{array}$ & 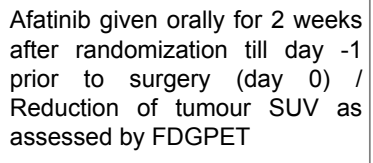 & recruiting & II \\
\hline NCT01824823 & $\begin{array}{l}\text { Afatinib After Chemoradiation and Surgery in } \\
\text { Treating Patients With Stage III-IV } \\
\text { Squamous Cell Carcinoma of the Head and } \\
\text { Neck at High-Risk of Recurrence }\end{array}$ & Afatinib $40 \mathrm{mg} /$ day p.o. 1y & $\begin{array}{l}\text { Adjuvant treatment in } \mathrm{N}+\text { pts } \\
\text { after CRT/ Examine DFS given } \\
\text { Afatinib/placebo adjuvant } \\
\text { therapy in patients with viable } \\
\text { tumours in lymph nodes after } \\
\text { neck dissection for suspected } \\
\text { residual disease after } \\
\text { concurrent CRT. }\end{array}$ & recruiting & II \\
\hline NCT01415674 & $\begin{array}{l}\text { Research of Biomarkers of Activity and } \\
\text { Efficacy of BIBW2992 in Untreated Non- } \\
\text { metastatic HNSCC Patients (PREDICTOR) }\end{array}$ & $\begin{array}{l}\text { A Afatinib from Day } 1 \text {, for } 14 \\
\text { to } 28 \text { days, depending on the } \\
\text { date of surgery }\end{array}$ & $\begin{array}{l}\text { Potential predictive biological } \\
\text { markers of activity of Afatinib } \\
\text { (biopsy: FISH;PCR; quantitative } \\
\text { RT-PCR; Imaging Response } \\
\text { FDGPET response (15d) } \\
\text { CT/MRI (21d)) }\end{array}$ & recruiting & ॥ \\
\hline NCT01427478 & $\begin{array}{l}\text { Evaluation of Afatinib in Maintenance } \\
\text { Therapy in Squamous Cell Carcinoma of the } \\
\text { Head and Neck (BIBW2992ORL) }\end{array}$ & $\begin{array}{l}\mathrm{RT}+\mathrm{CDDP} \\
\text { Afatinib } 100 \mathrm{yg}\end{array}$ & $\begin{array}{l}\text { Adjuvant treatment/DFS; QoL ; } \\
\text { safety; OS }\end{array}$ & recruiting & III \\
\hline NCT01783587 & $\begin{array}{l}\text { Safety Study of Afatinib and Postoperative } \\
\text { Radiation Therapy to Treat Head and Neck } \\
\text { Cancer }\end{array}$ & $\begin{array}{l}\text { Dose escalation of Afatinib + } \\
\text { docetaxel + RT }\end{array}$ & $\begin{array}{l}\text { Postoperative } \mathrm{RT}+\mathrm{CT}+\text { Afatinib / } \\
\text { safety }\end{array}$ & recruiting & 1 \\
\hline NCT01732640 & $\begin{array}{l}\text { A Phase I/II Study Afatinib/Carboplatin/ } \\
\text { Paclitaxel Induction Chemotherapy In HPV- } \\
\text { Negative HNSCC. }\end{array}$ & CBDA/PTX/A & $\begin{array}{l}\text { IC in HPV neg LA-HNSCC/ } \\
\text { ORR;MTD; safety }\end{array}$ & recruiting & $\mathrm{I} / \mathrm{II}$ \\
\hline
\end{tabular}


Citation: Denaro N, Merlano MC (2015) Profile of Afatinib and its Potential in the Treatment of Head and Neck Cancer: Current Evidence. J Oncol Transl Res 1:101

Page 4 of 5

\begin{tabular}{|c|c|c|c|c|c|}
\hline NCT00809133 & $\begin{array}{l}\text { Trial Exploring Afatinib (BIBW 2992) + } \\
\text { Paclitaxel (Part A), Afatinib + Paclitaxel + } \\
\text { Bevacizumab (Part B), Afatinib + } \\
\text { Carboplatin (Part C) and Afatinib+ Paclitaxel } \\
+ \text { Carboplatin(Part D) in Patients With } \\
\text { Advanced Solid Tumors }\end{array}$ & $\begin{array}{l}\text { A + PTX(part A); A + PTX + } \\
\text { Beva (Part B), A+ CBDA (Part } \\
\text { C) A+ PTX+CBDA(Part D) }\end{array}$ & Safety of the combination & completed & 1 \\
\hline NCT00716417 & $\begin{array}{l}\text { Study to Determine the Maximum Tolerated } \\
\text { Dose of BIBW } 2992 \text { (Afatinib) When } \\
\text { Combined With Cisplatin/Paclitaxel or } \\
\text { Cisplatin/5-FU in Patients With Advanced } \\
\text { Solid Tumors }\end{array}$ & $\begin{array}{l}\text { Ptx/CDDP/Afatinib ; ptx/5FU/ } \\
\text { afatinib }\end{array}$ & Safety; MTD & completed & $\mathrm{lb}$ \\
\hline NCT02171715 & $\begin{array}{l}\text { BIBW } 2992 \text { Administered as Tablet (Final } \\
\text { Formulation) Compared to BIBW } 2992 \\
\text { Drinking Solution and BIBW } 2992 \text { Tablet } \\
\text { (Trial Formulation II) in Healthy Male } \\
\text { Volunteers }\end{array}$ & $\begin{array}{l}\text { Afatinib } 20 \mathrm{mg} \text { tablet versus } \\
\text { drinking solution }\end{array}$ & $\begin{array}{ll}\text { bioavailability } & \text { and } \\
\text { pharmacokinetics } & \end{array}$ & completed & 1 \\
\hline NCT02020577 & $\begin{array}{l}\text { Trial of Afatinib (BIBW 2992) + Cetuximab in } \\
\text { Advanced Solid Tumours }\end{array}$ & Afatinib vs Cetuximab & ORR; DCR & completed & $\mathrm{lb}$ \\
\hline NCT02216617 & $\begin{array}{l}\text { Evaluation of the Tolerance of Afatinib in } \\
\text { Combination With Docetaxel and Cisplatin in } \\
\text { LAHNSCC Induction Chemotherapy (TAPIS) }\end{array}$ & afatinib /docetaxel /CDDP & $\begin{array}{l}\text { IC in LAHNSCC/ MTD in phase } \\
\text { l-efficacy vs TPF in phase II }\end{array}$ & recruiting & 1 \\
\hline NCT01856478 & $\begin{array}{l}\text { LUX-Head\&Neck 3: Afatinib (BIBW2992) } \\
\text { Versus Methotrexate for the Treatment of } \\
\text { Recurrent and/or Metastatic Head and Neck } \\
\text { Squamous Cell Cancer After Platinum } \\
\text { Based Chemotherapy }\end{array}$ & Afatinib vs MTX & $\begin{array}{l}2^{\circ} \text { line treatment/ PFS, Safety, } \\
\text { OS }\end{array}$ & recruiting & III \\
\hline NCT02131155 & $\begin{array}{l}\text { LUX-Head \& Neck 4: Afatinib (BIBW 2992) } \\
\text { Versus Placebo for the Treatment of Head } \\
\text { and Neck Squamous Cell Cancer After } \\
\text { Treatment With Chemo-radiotherapy }\end{array}$ & Afatinib vs Placebo & $\begin{array}{l}\text { Adjuvant treatment after CRT / } \\
\text { PFS; OS; QoL }\end{array}$ & recruiting & III \\
\hline NCT01345669 & $\begin{array}{l}\text { LUX-Head\&Neck 2: A Phase III Trial of } \\
\text { Afatinib (BIBW 2992) Versus Placebo for the } \\
\text { Treatment of Head and Neck Squamous Cell } \\
\text { Cancer After Treatment With Chemo- } \\
\text { radiotherapy }\end{array}$ & Afatinib vs Placebo & DFS;OS;QoL & recruiting & III \\
\hline NCT01345682 & $\begin{array}{l}\text { LUX-Head\&Neck 1: A Phase III Trial of } \\
\text { Afatinib (BIBW2992) Versus Methotrexate } \\
\text { for the Treatment of Recurrent and/or } \\
\text { Metastatic (R/M) Head and Neck Squamous } \\
\text { Cell Cancer After Platinum Based } \\
\text { Chemotherapy }\end{array}$ & Afatinib vs MTX & PFS; OS;QoL & published & III \\
\hline NCT00514943 & $\begin{array}{l}\text { BIBW } 2992 \text { (Afatinib) in Head \& Neck } \\
\text { Cancer }\end{array}$ & Afatinib vs etuximab & $\begin{array}{l}\text { Tumour shrinkage ; Safety; } \\
\text { laboratory parameters; } \\
\text { biomarkers; tumour shrinkage } \\
\text { after crossover; best RECIST } \\
\text { assessment; PFS; OS; QOL; } \\
\text { AEs. }\end{array}$ & published & II \\
\hline \multicolumn{6}{|c|}{$\begin{array}{l}\text { Abbreviations: p.o. per os; } \mathrm{DFS}=\text { disease free survival; } \mathrm{w}=\text { week; } \mathrm{N}+\text { node positive; } \mathrm{OS}=\text { overall } \\
\text { survival; } \mathrm{QoL}=\text { quality of life; } \mathrm{SUV}=\mathrm{Standardised} \text { Uptake Volume; } \mathrm{AE}=\text { adverse events; } \mathrm{MTX}= \\
\text { metotrexate; } \mathrm{PTX}=\text { paclitaxel; } \mathrm{CDDP}=\mathrm{Cisplatin} ; \mathrm{CBDA}=\text { carboplatin; } \mathrm{HPV}=\text { human } \\
\text { Papipllomavirus; } \mathrm{CT} \text { = computerized tomography; } \mathrm{MRI} \text { magnetic resonance imaging }\end{array}$} \\
\hline
\end{tabular}

Table 1: Afatinib in HNC trials ongoing and results from completed trials.

\section{Conclusion}

In the last few decades, a growing interest derived from the emerging data about both tumour biology and clinical trials. Several factors (pathological and molecular), affecting the behaviour and the prognosis, could allow a better definition of therapeutic protocol. Management should be planned according to the tumour's characteristics, pts factors and expertise of the medical team. To date, only six drugs have been FDA-approved for the treatment of HNSCC. Cetuximab is the only approved molecular targeting agent for HNSCC and despite ubiquitous expression of EGFR in, clinical responses are limited. Recent molecular breakthroughs in HNSCC and the use of new targeted therapies such as Afatinib provide much hope for future strategies. Although the modest improvement in PFS and no gain in 
OS in the published phase III trial the clinical benefit (in QoL and improvements in disease-related symptoms) justifies further investigation. Additionally the lack of cross-resistance between Cetuximab and Afatinib might have meaningful clinical implication in the next future. Disappointing results on OS might depend on subsequent therapies after progression, on patient's characteristics or activation of different pathways beyond EGFR. However the LUXH\&N 1 study with Afatinib is only the second positive trial that has been reported, in R-M HNSCC. Further studies are eagerly awaited. The results of these studies will define the role of Afatinib in the daily clinical practice.

\section{References}

1. http://www.cancer.org/acs/groups/content/@epidemiologysurveilance/ documents/document/acspc-036845.pdf.

2. Posner MR, Hershock DM, Blajman CR, Elizabeth Mickiewicz, Eric Winquist, et al. (2007) Cisplatin and fluoracil alone or with docetaxel in head and neck cancer. NEJM 357: 1705-1715.

3. Cohen EEW, Lingen MW, Vokes EE (2004) The expanding role of systemic therapy in head and neck cancer J Clin Oncol. 22: 1743-1752.

4. Adelstein DJ, Li Y, Adams GL, Wagner H Jr, Kish JA, et al. (2003) An intergroup phase III comparison of standard radiation therapy and two schedules of concurrent chemoradiotherapy in patients with unresectable squamous cell head and neck cancer. J Clin Oncol 21: 92-98.

5. Wolff HA, Overbeck T, Roedel RM, Hermann RM, Herrmann MK, et al. (2009) Toxicity of daily low dose cisplatin in radiochemotherapy for locally advanced head and neck cancer. J Cancer Res Clin Oncol 135: 961-967.

6. Agarwala SS, Cano E, Heron DE, Johnson J, Myers E, et al. (2007) Longterm outcomes with concurrent carboplatin, paclitaxel and radiation therapy for locally advanced, inoperable head and neck cancer. Ann Oncol 18: 1224-1229.

7. Puc MM, Chrzanowski FA, Tran HS, Liu L, Glicksman AS, et al. (2000) Preoperative chemotherapy-sensitized radiation therapy for cervical metastases in head and neck cancer. Arch Otolaryngol Head Neck Surg 126: $337-342$.

8. Koness RJ, Glicksman A, Liu L, Coachman N, Landman C, et al. (1997) Recurrence patterns with concurrent platinum-based chemotherapy and accelerated hyperfractionated radiotherapy in stage III and IV head and neck cancer patients. Am J Surg 174: 532-535.
9. Glicksman AS, Wanebo HJ, Slotman G, Li Liu, Christine Landmann, et al. (1997) Concurrent platinum-based chemotherapy and hyperfractionated radiotherapy with late intensification in advanced head and neck cancer. Int J Radiation Oncology Biol Phys 39: 721-729.

10. Greene FL (2002) AJCC Cancer Staging Handbook: From the AJCC Cancer Staging Manual. Springer, New York.

11. National Cancer Institute (2009) Common Terminology Criteria for Adverse Events v4.0. NCI, NIH, DHHS, NIH publication.

12. Bourhis J, Lapeyre M, Tortochaux J, Lusinchi A, Etessami A, et al. (2011) Accelerated radiotherapy and concomitant high dose chemotherapy in non resectable stage IV locally advanced HNSCC: Results of a GORTEC randomized trial Rad Onc 100: 56-61.

13. Castro G, Snitcovsky IML, Gebrim EM, Leitão GM, Nadalin W, et al. (2007) High-dose cisplatin concurrent to conventionally delivered radiotherapy is associated with unacceptable toxicity in unresectable, non-metastatic stage IV head and neck squamous cell carcinoma. Eur Arch Otorhinolaryngol 64: 1475-1482.

14. Rampino M, Ricardi U, Munoz F, Reali A, Barone C, et al. (2011) Concomitant adjuvant chemoradiotherapy with weekly low-dose cisplatin for high-risk squamous cell carcinoma of the head and neck: a phase II prospective trial. Clin Oncol 23: 134-140.

15. Paccagnella A, Ghi MG, Loreggian L, Buffoli A, Koussis H, et al. (2010) Concomitant chemoradiotherapy versus induction docetaxel, cisplatin and 5 fluorouracil (TPF) followed by concomitant chemoradiotherapy in locally advanced head and neck cancer: a phase II randomized study. Ann Oncol 21: 1515-1522.

16. Rivera F, Vega-Villegas ME, Lopez-Brea M, Isla D, Mayorga M, et al. (2008) Randomized phase II study of cisplatin and 5-FU continuous infusion (PF) versus cisplatin, UFT and vinorelbine (UFTVP) as induction chemotherapy in locally advanced squamous cell head and neck cancer (LA-SCHNC). Canc Chem Pharm 62: 253-261.

17. Goodman MD, Tarnoff M, Kain M, Slotman GJ, Southern New Jersey Head and Neck Cancer Treatment Group (1997) Interactions between outcomes and tumor response to preoperative cisplatin-sensitized radiotherapy in advanced head and neck cancer. Am J Surg 174: 527-531.

18. Argiris A (2013) Current status and future directions in induction chemotherapy for head and neck cancer. Crit Rev Onc Hem 88: 57-74.

19. Fortin A, Caouette R, Wang CS, Vigneault E (2008) A comparison of treatment outcomes by radiochemotherapy and postoperative radiotherapy in locally advanced squamous cell carcinomas of head and neck. Am J Clin Oncol 31: 379-383. 